\title{
An Intervention Study on Worm Infestation among School Going Children in Rural Areas of South India
}

\section{Devagappanavar G*}

Guest Faculty in School of Environmental Science, Public Health and Sanitation Management, India

*Corresponding author: Gulappa Devagappanavar, Guest Faculty in School of Environmental Science, Public Health and Sanitation Management, Panchayat Raj University, Gadag, India, Email: gulappa.md07dmr@gmail.com

\section{Research Article}

Volume 4 Issue 2

Received Date: March 16, 2021

Published Date: March 30, 2021

DOI: $10.23880 /$ jqhe-16000214

\section{Abstract}

Background: World Health Organization had estimated that about 1400 million people worldwide are infected with any one of the three kinds of intestinal helminths. They are a roundworm, hookworm and whipworm infestation. In that 200 million children suffer from diseases associated with these infestations. In India, 25 to 30 children's were positive with hookworm. The poor standard of living includes improper disposal of faecal and other wastes, overcrowding, unhygienic health practices and poor environmental sanitation are the reasons for the worm infestation among the children. The worm infestation will cause due to unhygienic practices that's why the Government of India started the National deworming day programme in 2015 with yearly two-phased observation to prevent the worm infestation. So in this study, we wanted to assess the knowledge about worm infestation among the service receiving children, servicing providing school teachers and civil society participation and cooperation.

Objectives: Assessment of knowledge about worm infestation among School Children, school teachers and General population. To assess the health education impact on the study participants.

Materials and Methods: A school-based cross-sectional intervention study was conducted to assessing the knowledge about worm infestation among the children, school teachers and general population using a pre-tested questionnaire. Systematic random sample, Universal sampling and convenient sampling technique were adapted to choose the students, teachers and community people respectively. The knowledge about worm infestation was assessed through pre-test and after providing the health education the Post-test was done using the same questionnaire for the same participants.

Results: Among the school children in the pre-test have $51.36 \%$ and in the post-test, it is increased to $83.73 \%$. In the pretest $57.11 \%$ and the post-test, it is increased $92.17 \%$ among the school teachers and the general population in the pre-test knowledge was $41.91 \%$ and it increased to $88.16 \%$ in the post-test.

Conclusion: Though the government of India started the national deworming day program in 2015, the knowledge about worm infestation is below 60 percent in the studied population. This study proved that health education is the key to improve their knowledge about worm infestation.

Keywords: Worm Infestation; Knowledge; Pre-Test and Post-Test; Hygienic Practices; Intervention Study; Karnataka 


\section{Introduction}

Deworming school-age children should be conceived as a part of a larger national strategy for the integrated control and elimination of worm infestation [1]. Parasitic worm infection disproportionately affects school-age children, with this age group showing the highest intensity and highest prevalence compared to any other age group [2]. Soil-transmitted helminthiases as a public health problem in children worm infections problems cause anaemia, poor physical growth, poor Intellectual development and impaired cognitive function, the infection reaches maximum intensity in the age range of 5 to 14 years [3]. India alone contributes nearly $25 \%$ to the total global cases with 220.6 million children in need of preventive chemotherapy $[4,5]$. Morbidity due to Soiltransmitted helminths (STH) infections can be controlled at a reasonable cost through mass deworming using effective drugs [6,7]. These parasitic infections distribution is variable from place to place, region to region depending upon the degree of personal and community hygiene participation and climatic factors [8]. In this study, we wanted to assess the impact of health education about worm infestation on study participants.

\section{Materials and Methods}

\section{Study Design}

A school-based Intervention Study was conducted in the North Karnataka Gadag district.

\section{Study Setting}

Data was collected in the rural area government schools using the Pre-test and Post-test Questionnaires. Study participants knowledge was assessed introducing the questionnaires and after providing the health education about worm infestation the same questionnaire was introduced to assess the impact of health education.

\section{Study Place}

Primary and high schools of Gadag Taluk, Gadag District

\section{Study Participants}

Students from $5^{\text {th }}$ standard to $10^{\text {th }}$ standard, School teachers, the general population from the study area villages

\section{Variables}

Dependent Variables: Variables were measured in the study is knowledge among the study participants about worm infestation.

\section{Independent Variable: Health Education}

Data sources: Primary data was obtained introducing the questionnaire to the study participants.

School Students: Questionnaire was introduced to every $3^{\text {rd }}$ student on their sitting order at the day of data collection.

School Teachers: All 5 village Government school teachers were approached for the study, those who have given consent to participate been included in the study.

General Population: Common congruence places of the village were selected to include the study participants.

Study Size: Totally 309 students, 73 teachers and 108 general populations were included in the study.

Statistical Methods: Data was entered into an excel sheet, analyzed using SPPS v20 and Expressed in frequencies and percentages.

Ethical Approval: Obtained from KSRDPR University, ethics committee.

\section{Results}

This study was conducted in rural settings as there was a perception that in the rural areas unhygienic condition and morbidity of the worm infestation was more.

In the present study 490 participants were included from the 5 villages. Among the majority of the participants are $7^{\text {th }}$ standard students, primary school teachers and General population (Table 1).

\begin{tabular}{|c|c|c|c|}
\hline Participants & Variables & Frequency & Percentage \\
\hline \multirow{6}{*}{$\begin{array}{l}\text { Students } \\
\text { n-309 }\end{array}$} & 5th Standard & 42 & 13.59 \\
\hline & 6th Standard & 37 & 11.97 \\
\hline & 7th Standard & 74 & 23.94 \\
\hline & 8th Standard & 65 & 21.03 \\
\hline & 9th Standard & 66 & 21.35 \\
\hline & 10th standard & 25 & 8.09 \\
\hline Teachers & Primary school & 41 & 56.16 \\
\hline$n-73$ & High school & 32 & 43.83 \\
\hline \multirow{2}{*}{$\begin{array}{c}\text { General } \\
\text { population } \\
\text { n-108 }\end{array}$} & $\begin{array}{c}\text { Panchayat } \\
\text { Members }\end{array}$ & 34 & 31.48 \\
\hline & $\begin{array}{c}\text { General } \\
\text { population }\end{array}$ & 74 & 68.51 \\
\hline
\end{tabular}

Table 1: Distribution Characteristics of Study participants.

It was found that nearly half of the school students have poor knowledge, more than half the school teachers have average knowledge and $1 / 3^{\text {rd }}$ of the general population have poor knowledge about worm infestation (Table 2). 


\begin{tabular}{|c|c|c|c|}
\hline Variables & Knowledge Scale & Frequency & Percentage \\
\hline \multirow{3}{*}{ Students } & Poor & 133 & 43.04 \\
\cline { 2 - 4 } & Average & 106 & 34.3 \\
\cline { 2 - 4 } & Good & 70 & 22.65 \\
\hline \multirow{3}{*}{ Teachers } & Poor & 16 & 21.91 \\
\cline { 2 - 4 } & Average & 43 & 19.17 \\
\cline { 2 - 4 } & Good & 14 & 76.85 \\
\hline \multirow{3}{*}{ General Population } & Poor & 83 & 17.59 \\
\cline { 2 - 4 } & Average & 19 & 5.55 \\
\cline { 2 - 4 } & Good & 6 & \\
\hline
\end{tabular}

Tables 2: Knowledge among study participants.

In the current study, it was found that the knowledge about worm infestation was increased drastically after the provision of health education among the school children
(Figure 1).

- Scoring Scales: 1-3- poor, 4-6-Average, 7-9-Good

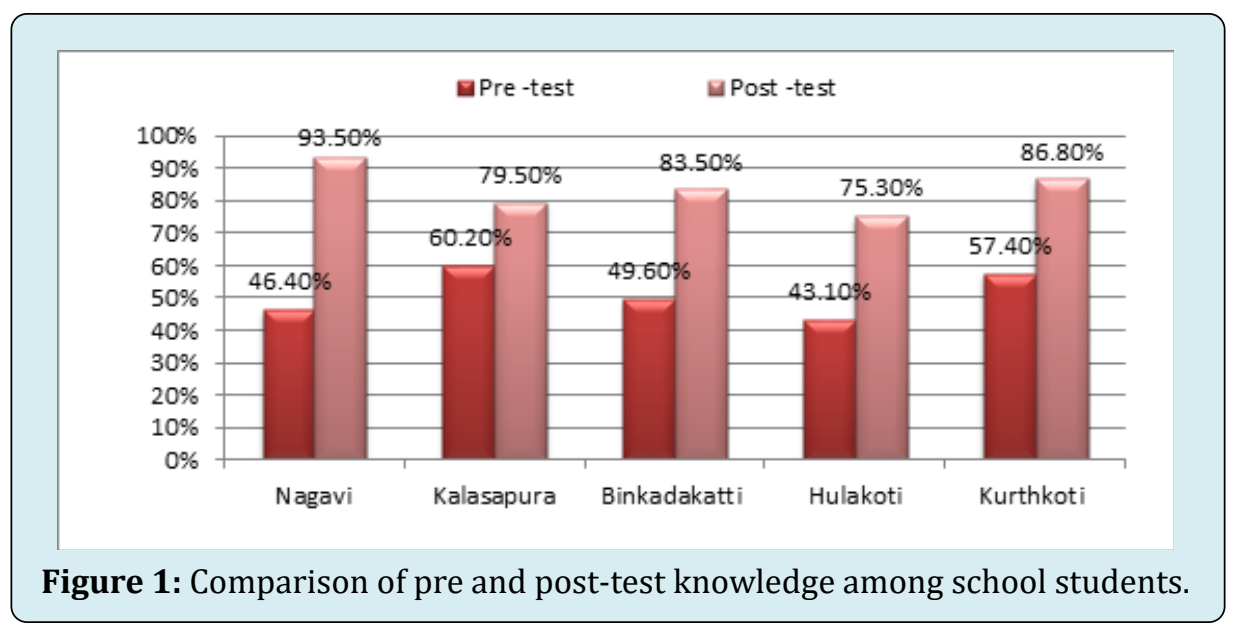

Findings of the study revealed that knowledge about worm infestation was increased more than half percentage among the school teachers compare to their previous knowledge (Figure 2).



Figure 2: Comparison of pre and post-test knowledge among Government Employees. 
It was found that the knowledge about worm infestation was increased more than half percentage among the general

population (Figure 3).

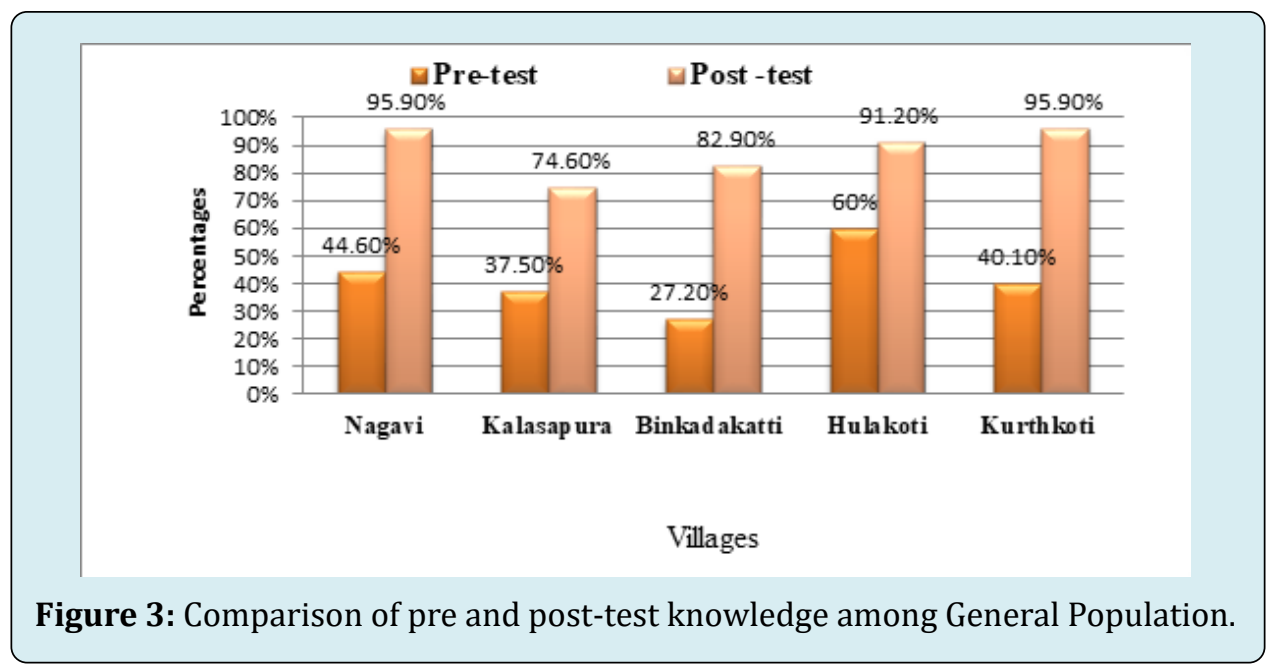

In the overall findings, the knowledge about worm infestation was increased among all study participants and the Consumption of Albendazole tablets was increased to $99.5 \%$ which was less in the previous year $91.6 \%$. This showed that health education was made an impact on the study participants.

\section{Discussion}

\section{Study Population}

This study was conducted in the rural settings on School going children, teachers and the general population. A similar study conducted at Bihar in rural settings [5] and another study on children in a rural setting at China [9].

\section{Pre-Test Knowledge}

In the current study, $43.04 \%$ of the school students have poor knowledge about worm infestation. A similar result was shown in a study conducted at Mangalore [10]. The same findings found in the qualitative study conducted at Kenya the similar findings found in different Indian states, Kancheepuram district Tamilnadu in Uttar Pradesh Rajasthan Kashmir and Bhopal [11-17].

$58.90 \%$ of the school teachers have average knowledge about worm infestation, a similar study conducted in Kenya found similar findings and in Tamil Nadu $[8,12]$. The role of school teachers was very important to effective control in worm infestation, the similar advise found in the World health organization report mentioned about the role of school teachers in the implementation of deworming activities [1]. A similar opinion was found a study conducted at Kenya(18) and in the World Health Organization manual for school teachers [19].

$76.85 \%$ of the general population have poor knowledge about worm infestation, a similar study conducted in Punjab found that $40 \%$ of the population have below-average knowledge [20]. The role of civil society participation is very important to the implementation and success of the programs. A similar study conducted at Gujarat Andhra Pradesh and Punjab showed the same opinion [21].

\section{Impact of Health Education}

The knowledge about worm infestation was significantly increased among the school students in all the five villages. The similar and significant result found in review report prepared by Imperial College at London, UK [2]. Another study conducted in south India at Tamilnadu showed the same impact on the school children the similar study conducted at China found a significant impact on school children $[7,12,22]$.

In the world, health organization manual for conducting a school deworming day explained the role of school teachers [19]. The health education showed positive impact among the school teachers on worm infestation, the similar result found the study in conducted in the corporate schools of Tirupati, Tamilnadu the similar impact showed in a study conducted at another Neighboring country Nepal and in Australia [23-25].

Among the General population knowledge about worm infestation was increased significantly, The similar study conducted on mothers at Tamilnadu showed similar impact [26] and at Kenya [11]. 


\section{Conclusion}

The present study proved that the provision of health education will impact on the study participants. Henceforth if we provide continuous health education then definitely we can achieve $100 \%$ coverage in all national health programmes.

\section{Acknowledgement}

I would like to acknowledge all my Master of Public Health Scholars and Prof. Dr. Suresh V Nadagoudar Acting Vice-Chancellor and Registrar of Karnataka State Rural Development and Panchayat Raj University, Gadag for their support.

\section{References}

1. World Health Organization (WHO) (2011) Helminth control in school-age children: a guide for managers of control programmes. $2^{\text {nd }}(E d n$.).

2. Partnership for Child Development (PCD) (2016) Imperial College London. Guidelines for School -based Deworming programs. pp: 1-20.

3. (2005) The evidence is in: deworming helps meet the Millennium Development Goals enrolment. pp: 2.

4. Salam N, Azam S (2017) Prevalence and distribution of soil-transmitted helminth infections in India. BMC Public Health.

5. Pandey BN, Kumar DVD (2013) Epidemiological study of parasitic infestations in rural women of Terai belt of Bihar, India. Ann Biol Res 4(10): 30-33.

6. Gupta MK, Singla S (2017) Deworming among preschool and school-going children in a rural area: a crosssectional survey. IJCMPH 4(10): 3777-3780.

7. Bieri FA, Gray DJ, Williams GM, Raso G, Li YS, et al. (2013) Health-education package to prevent worm infections in Chinese schoolchildren. N Engl J Med 368(17): 16031612.

8. Tenali RK, Badri NK, Kandati J, Ponugoti M (2018) Prevalence of intestinal parasitic infections in cases of diarrhoea among school children attending a tertiary care hospital: a two-year study. Int J Contemp Pediatr 5(3): 873-878.

9. Guan M, Han B (2019) Association between intestinal worm infection and malnutrition among rural children aged 9-11 years old in Guizhou. BMC Public Health 19(1204): 1-11.
10. Hemant B, Retd K, Kalpana C, Retd J, Rahul M (2014) A study of the prevalence of intestinal worm infestation and efficacy of anthelminthic drugs. Med J Armed Forces India 70(2): 144-148.

11. Masaku J, Mwende F, Odhiambo G, Musuva R, Matey E, et al. (2017) Knowledge, practices and perceptions of geo- helminths infection among parents of preschoolage children of the coastal region, Kenya. PLoS ONE Neglected Trop Dis, pp: 1-18.

12. Bhuvaneswari G (2014) A study to assess the effectiveness of teaching programme on roundworm infestation among middle school children at a rural setting. IOSR-JNHS 3(2): 1-5.

13. Awasthi S, Peto R, Read S, Richards SM, Pande V, et al. (2013) Population deworming every 6 months with albendazole in 1 million pre-school children in north India: DEVTA, a cluster-randomised trial. Lancet 381(9876): 1478-1486.

14. Choubis SL, Jaroli VJ, Pallavi Choubisa NM (2012) Intestinal parasitic infection in Bhil tribe of Rajasthan, India. J Parasit Dis 36(2): 143-148.

15. Singh C, Zargar SA, Masoodi I, Shoukat A, Ahmad B (2010) Predictors of Intestinal parasitosis in school children of Kashmir: A prospective study 31(2): 105-107.

16. Wani SA, Ahmad F, Zargar SA, Fomda BA, Ahmad Z, et al. (2007) Helmenthic Infestation in Children of Kupwara District: A prospective study. Indian J Med Microbiol 25(4): 398-400.

17. Nema S (2014) Intestinal Parasitic infections and Demographic status of school children in Bhopal region of Central India. OOSR-JBPS 9(5): 83-87.

18. Njomo DW, Masaku J, Odhiambo G, Musuva R, Mwende F, et al. (2016) The role of pre-school teachers in the control of soil-transmitted helminths in a coastal region, Kenya. Trop Dis Travel Med Vaccines 2: 24.

19. World Health Organization (2013) Conducting a school deworming day: A manual for teachers. pp: 31.

20. Sharma R, Sharma P (2014) A Comparative study to assess the knowledge regarding worm infestation in children among urban and rural mothers attending OPD in guru teg bahadur sahib (c) hospital, Ludhiana, Punjab. Int J Curr Res 6(7): 7647-7650.

21. Shobha M, Bithika D, Bhavesh S (2013) The prevalence of intestinal parasitic infections in the urban slums of a city in Western India. J Infect Public Health 6(2): 142-149. 
22. Mcmanus DP, Bieri FA, Li Y, Williams GM, Yuan L, et al. (2015) Health education and the control of intestinal worm infections in China: a new vision. Parasit Vector 7: 344.

23. Priyanka KM, Sreelatha M, Sudharani P (2017) A study to assess the knowledge of deworming practices among school teachers in corporate schools. Int J Appl Res 3(8): 653-656.

24. Medical C, Issn S (2015) Knowledge and practice of worm infection among mothers of school-going children of Arba VDC 190-195.

25. Bieri FA, Li Y, Yuan L, He Y, Gray DJ, et al. (2014) SchoolBased Health Education Targeting Intestinal WormsFurther Support for Integrated Control. PLoS ONE Neglected Tropical Diseases 8(3): e2621.

26. Prathaban S (2010) A study to assess the knowledge and practices regarding worm infestation among the mothers of school-age children (6-12 years ) to develop health education pamphlet at Paruvachi, Erode District. 